\title{
THE DIAGNOSIS AND TREATMENT OF URETHRITIS AND CERVICITIS IN THE FEMALE.*
}

By D. COCHRANE LOGAN, M.D., B.S.

Mr. Chairman, Ladies and Gentlemen :

I wish to make it clear that I have no formal paper to read to you on the subject of urethritis and cervicitis.

When I was asked to speak to you I stated that the more experience I gained in this subject the less did I feel able to make definite statements thereon-the more in fact did I become one big question mark. However, I was assured that some of the questions that had arisen in my mind might be of interest to my fellow members, and I therefore venture to put before you a few odd facts that I have observed, and to ask your help in answering the questions they have raised.

In the first place, I have no illusions. One's friends in other branches of surgery are apt scornfully to remark: "In your job, in the end the diagnosis is only your own pious opinion "- and to a very large extent they are right.

I hope, however, to mention a few cases where subsequent events have seemed to bear out that opinion when based only on slender evidence. Of course, in the average case, finding the gonococcus in a discharge seems fairly conclusive, but even so there are occasional traps for the unwary.

A colleague with whom I was working some years ago was treating a mother and child for vaginal discharge. The microscopic report was " gonococci present," but the patients did not respond to her usually successful method of treatment. A complement fixation test proved negative, and further microscopic investigations showed the organism to be the pneumococcus!

As regards the standard of diagnosis, I must frankly

* Based upon an address delivered before the Medical Society for the Study of Venereal Diseases, on January 29th, I926. 


\section{BRITISH JOURNAL OF VENEREAL DISEASES}

say that legally and clinically I am conscious of a wide divergence-e.g., to state positively " this is gonorrhœa" -knowing that divorce proceedings might turn upon that statement-requires undoubted microscopic and clinical evidence; but to wait for such complete evidence before treating a patient on anti-gonococcal lines would leave untreated the vast majority of women suffering from conditions originated by the gonococcus.

As an illustration of this, during my first year in charge of the Women's Gonorrhœa Department at King's College Hospital, there were 75 new patients. Of all the microscopic examinations made during the year, there were only four reports "gonococci present," although there were some 50 cases clinically positive!

In endeavouring to arrive at a diagnosis, every possible aid is sought. A careful history is taken, including the onset of symptoms, the patient's own opinion as to possible cause (often illuminating, if unscientific or even improbable), and the health of the partner. An equally thorough examination, general and local, including blood for a gonococcal complement fixation test, is made, whilst inspection and palpation of all passages and glands likely to be attacked is carried out.

Any abnormality must be noted and its value assessedmere redness of urethra that looks dull and of long duration must not be ignored ; a caruncle of any kind should be noted. On occasion a whole dram of pus may be expressed from a urethra which on mere inspection looks perfectly healthy.

Signs of inflammation in the glands, or pus expressed from Bartholin's ducts, makès one expect the presence of the gonococcus in a concurrent urethritis or cervicitis.

When the patient is non-V-I, and the inflammation is obviously not confined to the surface, a Cusco's speculum is passed and the vagina, fornices and cervix are examined.*

We have long since disabused our minds of the textbook description of gonorrhœa as a disease accompanied by a thick greenish purulent discharge-it may be, but we have had reports " gonococci present " in :

(a) A case which showed no symptoms or signs of any kind ;

* NotE.-By stretching the fornices and thus everting the os, the Cusco may tend to slightly exaggerate a split or eroded cervix. 


\section{URETHRITIS AND CERVICITIS}

(b) A case where all signs and symptoms had cleared up and all parts appeared perfectly healthy ;

(c) In one where there was only a slight old erosion of cervix, without any discharge, or symptoms, and no history of trouble of any kind at any time (merely a history of possible risk of infection two years before, and the patient was now referred as being the probable source of her present partner's acute infection);

(d) One where an excess of clear mucus from the endocervix was the only abnormality ;

(e) Where a mucoid discharge was present;

$(f)$ Where there was thin yellow, or thick yellow, pus or mucopus.

This routine examination includes the taking of films from all parts - urethra, vagina and cervix, Skene's and Bartholin's ducts, if any secretion can be expressed therefrom.

At a discussion on " Vaginal Discharge " held in London many months ago, a pathologist stated that he considered it to be a waste of time to examine a slide labelled " vaginal."

In view of this remark, it is interesting that at King's College Hospital during the past year there have been three reports "gonococci present " in the vaginal when they were not found in the urethral and cervical films taken at the same time-in one of these cases the patient feared herself reinfected, and-immediately came for examination because her husband had had a relapse. Gonococci were subsequently found in urethra and cervix, but they were first discovered in the vagina. There have been at least four other instances of the vaginal films giving the earliest help.

I have been very fortunate in the collaboration of kindly pathologists, who make no complaint of the large amount of work I send them. Dr. Creed, of King's College Hospital ; Dr. Rosher, of Charing Cross Hospital ; and Dr. T. H. C. Benians, of Tottenham, have done most of the work for me.

A bimanual examination of the pelvic organs completes my investigations, for the condition of uterus and appendages is of much importance - the near approach, or recent cessation of menstruation, a retroversion, pregnancy or tumours, may modify or increase normal secretion, while signs of inflammation may be valuable adjuncts to diagnosis. 


\section{BRITISH JOURNAL OF VENEREAL DISEASES}

Yet, after all this, I am not usually prepared to give a definite diagnosis of gonorrhœa on one examination, and I do not believe one is ever justified in giving a negative diagnosis on a single examination, even if the patient is free from symptoms.

I remember a case which was examined at the same time by my assistant and me, the assistant writing up the notes while I made the investigations. Pus was present in the urethra, Bartholin's, vagina and cervix. The patient had treatment by pot. permang. sitz baths only for one week, and returned looking so absolutely healthy -no pus, no redness anywhere-that one could have imagined the original notes applied to some one else. Any one seeing her on this second occasion only could easily have said " normal."

Recently I have had two different couples, each a mother and child. The children, clinically, appeared to be suffering from gonorrhœa, and I was surprised to have a negative report, but subsequently, in both mothers and children, gonococci were found-in one couple two days after the negative report.

I endeavour to take at least three sets of slides-but even this does not ensure certainty, as witness a recent case in whom three specimens, taken at weekly intervals, proved negative. I did not see her again for a month, and then found definite pus in the urethra and Bartholin's duct - and gonococci were found. There was no apparent reason for the altered condition, and the patient felt no discomfort and made no complaint, so, if we had remained satisfied with our three negative results, the condition would have been missed. (The possibility of infection subsequent to the three previous investigations is, I think, remote, as the girl was in a hostel under constant supervision.)

I am well aware how little help films may give, but it seems essential to endeavour to get this help by taking films at the original examination before starting treatment, and advisable to continue taking them at frequent intervals, though it is never right to delay treatment for the purpose of taking more " untreated " films, in any clinically suggestive case.

I have given these details to show that I make all possible efforts to obtain evidence for my " pious opinion."

My conclusion is that, in those cases which find their 


\section{URETHRITIS AND CERVICITIS}

way to a V.D. Dept., the gonococcus is by far the commonest cause of urethritis and cervicitis. Although in the more chronic cases it may be difficult to find, or may have disappeared, yet often the symptoms do not respond to treatment unless the latter be particularly directed against the gonococcus which one cannot find!

Treatment.-This must include relief of worry, sufficient rest, proper nourishment, regulation of bowels, sufficient fluid, appropriate medicines, cod-liver oil and malt, etc., and, where possible, change of air-everything which will tend to improve the general health.

I have been so satisfied with the results of vaccines (using a stock polyvalent vaccine of many good strains, prepared by Dr. Rosher), that I have extended its use from a routine in cases in which gonococci were found to all in which the clinical picture suggested gonorrhœea, unless there were some special contraindication.

I try to avoid getting a reaction, local, focal or general, and in suitable cases increase my dosage steadily up to I,000 millions; this has appeared to give the best results.

I am very careful to exclude salpingitis-or to get this quiescent-before starting vaccine, and if there has been any suspicion of a salpingitis, I take the patient into hospital until the first few doses have been given.

For some two years I tried detoxicated vaccine, but was not so satisfied with my results.

Autogenous (secondary organisms) vaccine I have found useful in some cases with persistent symptoms.

Collosal manganese has also proved useful.

Locally I have tried many applications, and on the whole consider that protargol remains one of the most useful in average cases; certainly such bland, nonirritating substances are best, but variety is essential in any case not readily responding to treatment.

Glycerine is by far the best basis, and ro per cent. protargol in glycerine one of the most useful forms-either for swabbing out, on vaginal packs, or as pessaries.

I do not like douches, save as given by a skilled nurse, with low pressure, long and hot (at least 2 quarts, up to II $5^{\circ}$ to $I 20^{\circ}$, if patient can stand it), for the purpose of applying heat in pelvic complications.

I consider that frequent irrigation of the urethra is essential for the removal of discharge-but by nature's method, not from outside. The patient is directed to 


\section{BRITISH JOURNAL OF VENEREAL DISEASES}

drink abundant water, and barley water, and to micturate as frequently as possible during the day, sedatives being given when this is painful, mild diuretics-pot. cit., with hyoscyamus, or hexamine, being prescribed in many cases.

An average local treatment consists in swabbing off the vulval surface ; swabbing out the urethra ; irrigating Skene's periurethral and Bartholin's ducts when indicated (through a fine lachrymal cannula). The vagina is mopped out through a Cusco's speculum, the cervical canal is swabbed out, and a vaginal pack is inserted and removed I2 to 24 hours later and renewed daily or less frequently according to the severity of the symptoms.

Frequent sitz baths (weak pot. permang., I-IO,000) are given.

In acute cases rest in bed is most valuable. Of various applications, protargol, mercurochrome, ichthyol, iodine, sulphur, borax, sod. bicarb. have all proved useful.

Erosion of the cervix must be treated frequently and with much patience, and is not likely to heal while an irritating discharge from above persists.

I think that in the treatment of gonococcal urethritis and cervicitis it is essential that treatment be persisted with even after symptoms subside - a too early cessation is likely to be followed by troublesome relapse.

It is with this general background of observations and opinions that I come to you with my illustrative cases and questions.

In looking through the microscopic reports for the past year, I found that many pages of the book were blank of " positives," but in July and September there were sometimes two positives on one page! This made me at first wonder if the hotter summer spells had been accompanied by an increased finding of the gonococcus.

I therefore investigated the number of new cases in each month, the number of new cases in which gonococci were found, the number of new cases " clinically positive."

The results are shown in the accompanying table, and the percentages show that the excess of pathological findings was apparent, not real.

Nevertheless, it has raised the question as to whether hot dry weather, while doubtless increasing the possible opportunities for infection, might also enable the delicate gonococcus to survive more easily. If this were so, one 


\section{URETHRITIS AND CERVICITIS}

\begin{tabular}{|c|c|c|c|c|c|}
\hline \multicolumn{2}{|c|}{ Month. } & $\begin{array}{l}\text { New } \\
\text { Cases. }\end{array}$ & Non-V.D. & Clinical G. & Gonococci present. \\
\hline January & & 5 & $3=60 \%$ & $2=40 \%$ & 0 \\
\hline February & & I5 & $7=46 \%$ & $7=46 \%$ & $2=13 \%$ \\
\hline March . & & Io & $4=40 \%$ & $5=50 \%$ & $\mathrm{I}=\mathrm{I0} \%$ \\
\hline April & & I6 & $9=68 \%$ & $7=43 \%$ & 0 \\
\hline May & & 8 & $3=37 \%$ & $5=62 \%$ & 0 \\
\hline June & & 9 & $3=33 \%$ & $4=44 \%$ & $2=22 \%$ \\
\hline July & & 30 & $18=60 \%$ & $7=23 \%$ & $5=\mathrm{I} 6 \%$ \\
\hline August . & & 5 & $2=40^{\circ} \%$ & $\mathrm{I}=20 \%$ & $2=40 \%$ \\
\hline Septembe & & IO & $I=10 \%$ & $5=50 \%$ & $4=40 \%$ \\
\hline October. & & I4 & $4=28 \%$ & $6=42 \%$ & $4=28 \%$ \\
\hline Novembe & & 5 & $2=40 \%$ & $3=60 \%$ & 0 \\
\hline Decembe & . & 7 & $3=42 \%$ & $4=57 \%$ & 0 \\
\hline
\end{tabular}

would expect a greater proportion of accidental infections under such circumstances-e.g., in children (not assault cases). Has any one found this to be the case ?

Remembering the difficulty in finding the gonococcus in the female, and the tragedies of infection occurring long after a supposed cure, how are we to know when a patient is cured?

We have had definite cures in many cases which have stood the test of marriage without relapse or infection of partner, but what can we say of a case such as the following ?-

In I920 I took over a patient who had been under treatment for a short time. I treated her thoroughly, including a course of detoxicated vaccine, and all of her symptoms cleared up. I watched her for many months after ceasing treatment, and took many provocative films (all negative), and was about to tell her that she need not come any more, when she said she was three months pregnant. Therefore I told her to report every fortnight. She continued to look perfectly clean, so much so that I recommended her for admission to an ordinary maternity ward, and the obstetrician examining her (once only) said there was no evidence of gonorrhœa.

She had a normal confinement (there was no ophthalmia), but she developed a "white leg" on the fifth day. She came to see me after six weeks. She still looked perfectly healthy-and gonococci were present in the films !

She had had intercourse once since confinement, so her husband was overhauled. He was free from infection.

If she had had a relapse, why had he not become v.D. 


\section{BRITISH JOURNAL OF VENEREAL DISEASES}

infected? If she had been reinfected, how could the disappearance of his infection be explained? In either case she had no symptoms and looked perfectly normal, and has remained so for the last eighteen months, during which time there has not been any " positive" report. When may I regard her as "cured," and is it possible that she may be a "carrier" and continue to be a potential source of infection?

Having in consideration how very little there may be to show for an infection, even in the early stages in which gonococci are present, what is the significance of certain things found later in patients, e.g., a caruncle, or redness of urethra?

I have one patient who first came for treatment in I922. There was pus in the periurethral glands and urethra, the posterior wall of which was red and prolapsed. There was a wide erosion of cervix. Gonococci were present February and April, I922. Except for a slight discharge from urethra in October, I923, symptoms had all cleared up in a few months-no signs of discharge, erosion healed ; no trouble of any kind except an old, dull red, small, tender, broad-based caruncle just within the meatus. What is the significance thereof? Does it indicate lurking active trouble, or is it merely an inactive scar? What is best to be done with this? Is removal by excision or by cautery to be advocated ?

Another case, et. 36, was sent by her doctor on June 4th, I923, because she was " red about urethra." She thought that she was probably infected some twenty years ago; she had received no treatment and had noticed a discharge for fourteen years, and had been feeling sore since an attack of influenza two months ago.

There were large macules at the urethra, especially around the orifice of the left Skene duct, and small macules at the orifice of Bartholin's duct. The cervix was slightly red, and only slight mucoid discharge. Pelvis n.a.d. No gonococci found. Complement \pm . She had been under treatment and observation. The redness seemed sometimes to improve, but it was not until April, I925 (when the patient felt seedy after influenza and bronchitis), that a thin drop of discharge was expressed from the left Skene duct, and has been obtained at times since. In view of the maculæ and weak positive complement and the long history, how 


\section{URETHRITIS AND CERVICITIS}

should this be regarded? Is the condition merely that of an old inactive scar of no importance, or does the persistent red patch mean something active which might light up and give more trouble?

Another case. Three years ago, when $\frac{5}{12}$ pregnant, the patient complained of some discharge with rather sudden onset, since marriage eighteen months before.

The urethra showed "old redness." There was a slight mucoid discharge from endocervix - not very much to find, but the report stated "on history treat as positive." No gonococci found, but complement was reported very weak + , and there were some slight cardiac symptoms which were due to a mild toxic myocarditis. The local symptoms cleared up with treatment, and general condition improved. Confinement was normal ; there was no ophthalmia.

The patient was seen once after confinement (looking clean), and then was lost sight of until a few months ago, when she came again for examination because the child had some discharge and she was worried because the husband had V.D. in the war and now had a slight relapse. The patient had not known this till recently because her husband had been told he was quite cured and fit to marry. Examination showed only slight stickiness in child (? due to thread-worm irritation). No gonococci were found.

The patient now looked healthy; the urethral redness had quite disappeared, the cardiac condition had cleared up, and the complement fixation reaction had become negative.

Does this appear to suggest that the condition found three years ago, viz., urethral redness, myocardial toxæmia, and weak positive complement, did indicate active trouble, and that one's " pious opinion " resulting in appropriate treatment was justified ?

In view of these last two cases, what is one to think of as to a possible diagnosis, and most appropriate treatment of a patient who gives a history of "rheumatism " since last confinement seven years ago; who has a toxic myocarditis (not a typical rheumatic heart), and who has a strongly positive gonococcal complement, with old redness of urethra? Might treatment on anti-gonococcal lines help to clear up the otherwise unexplained rheumatism and myocardial toxæmia? 


\section{BRITISH JOURNAL OF VENEREAL DISEASES}

Unfortunately this patient, being a Jewess, is convinced that only an undertaker can be of any service to her, and gives me no opportunity to apply a therapeutic test.

I have not found cystitis at all a common complication. I have no definite case to record for the past five years. One of my patients had urethritis and cervicitis (gonococci present), and I was treating her as an in-patient for rather severe salpingitis of the type that threatened to become a pyosalpinx.

One day the house surgeon reported that the patient had suddenly become much worse and was suffering from acute cystitis, that micturition was very frequent and painful, and that she was passing blood and pus. I had horrible visions of a missed pyosalpinx discharging through the bladder!!

However, examination showed pelvic condition I.S.Q. ; there was no sign of vesical tenderness, but the urethra was much more acutely inflamed than before. The most acute symptoms, which had appeared coincidently with a sore throat, began to abate after twenty-four hours. There were at the same time several other cases of sore throat in the adjacent ward. We concluded that the supposed "cystitis" was an acute exacerbation of urethritis, probably caused by the same secondary organisms as those responsible for the sore throat.

One of the other problems one meets is that of the old infection, long quiescent, apparently lighting up after many years, and for no known cause. I will give an example. A woman, married twelve years, two children, et. ten years and nine months, c/o discharge. I found pus in the urethra-gonococci were present-and I referred her for treatment to her local hospital V.D. clinic without telling her the nature of the trouble. Subsequently she came to me for an explanation, saying she had gone straight home from the clinic and had a thorough row with her husband because it had been necessary for her to go to such a place, but he had declared himself perfectly healthy and innocent of any offence.

We discussed all possible sources of recent accidental infection, and she could not think of any; she had had no trouble during pregnancies and labours. There had been no ophthalmia. Her husband was examined and proved healthy.

I think there was no possibility of recent infection due I 78 


\section{URETHRITIS AND CERVICITIS}

to her own fault. In such a case, learning the nature of her trouble, she would surely have come for advice as to how to get treatment without his knowledge rather than have first told him about it.

Her only possible explanation was that as a young girl (some fifteen years or more ago) her mother had taken her to St. Thomas' for some treatment which she did not understand at the time, following upon a thorough scolding for using a lavatory at an inn which she had been forbidden to use on the score of uncleanliness. While she was still under treatment her mother had died, the matter had dropped, and she had thought no more about it, and seemed surprised to learn that the present trouble might be a sequel.

But, if so, why the present symptoms of trouble so long in abeyance? Why the escape of partner from infection? Has he some special immunity? Might she have proved infective to another partner?

Her symptoms have cleared up with careful treatment, and she has had no, relapse in five years-but may she be considered cured ?

Another type on which I should like your opinion is illustrated by the following case :-

The patient was first seen in 1923 when $\frac{7}{12}$ pregnant, with a slight white discharge of three weeks' duration, which was gradual in its onset.

Examination showed that the urethra was normal. Right Bartholin gland was palpable. There was mucopus in the vagina. The cervix was eroded, and there was a mucoid discharge from the endocervix. W.R. and comp. negative. Films: Pus ++ ; no gonococci.

She was treated with mercurochrome and protargol, and given vaccine up to a 200 million dose before confinement. On October IIth, I923, it was stated that she had a profuse offensive discharge during labour, but that no untoward results had accrued to herself or her babe. She was seen again on November 7 th, I923, when urethral and cervical films showed pus + . She did not attend again till September 9th, I925, when she stated that she had had hardly any discharge and that she was now nearly six months pregnant. Her rest had been disturbed for ten nights by a severe pruritus accompanied by a slight discharge, which caused soreness. Her husband was also suffering from irritation with " blisters." 


\section{BRITISH JOURNAL OF VENEREAL DISEASES}

On examination a severe intertrigo was found. The urethra and Bartholin's ducts were normal. There were a strong acid secretion at the vaginal orifice and slightly acid mucopus in vagina. After treatment with sod. bicarb. the irritation diminished, but the rash spread over abdomen, thighs and buttocks. General treatment was given, sulphur was applied locally, but no improvement occurred until October 22nd, I925, when protargol was applied.

The first dose of vaccine was given on November $3 \mathrm{rd}$, I925, and symptoms immediately subsided, though considerable mucopurulent discharge from the cervix continued until after a dose of 500 millions was given on December I5th, I925. The vaccine treatment was continued until 800 millions had been given before the patient's confinement, which took place on January 7 th, I926. Delivery and puerperium were then normal. There was no discharge and no ophthalmia.

Why should such a case, in which gonococci were not found (nor, on one examination, in husband), fail to respond to anything but specifically anti-gonococcal treatment, local and general ?

There is one more case of slightly unusual interest.

Patient, at. 28, was first seen in November, I925, $\frac{7}{12}$ pregnant, complaining of pain over lower extremities of tibiæ of one week's duration. She had had a slight yellow discharge for four months, also had "ulcers of back passage" (? due to falling down) for two months. One year ago there was a history of " rheumatism" for two months from August, I925. Examination showed a pigmented scar on right side of anus, a slight intertrigo; a scanty white discharge was expressed from the urethra, and there was a slight white vaginal discharge. There were no skin lesions, nor scarring of throat; the patient looked ill.

The W.R. was negative. Gonococci were present in urethral, vaginal and cervical films taken November IIth and I7th, I925. An enquiry as to rheumatism gained the following report from another hospital: "Slight temperature on admission. $R$. wrist and $R$. knee joints swollen and tender. Diagnosis - Acute rheumatism. Later-slight œdema $R$. foot-cause not found. Discharge not mentioned by patient, and not investigated."

The " ulcers of back passage " were reported as " periI 80 


\section{URETHRITIS AND CERVICITIS}

anal abscess, no special cause known; gonococci not looked for.'"

I have not found gonococci in anal films, and there has been no anal discharge whilst the patient has been under my care, but I have rather wondered if that original trouble, as well as the acute rheumatism, may all have been a part of the gonorrhœal attack.

These few remarks and notes of odd cases I leave with you and would ask your comments thereon. The chief questions which have arisen relative thereto are :-

(I) In women, what should be the standard of diagnosis for purposes of treatment ?

(2) When can a patient be safely regarded as cured, i.e., not only free from symptoms, but from risk of relapse or carrying infection?

(3) What is the significance of the gonococcal complement fixation test in women?

(4) Has climate and temperature any influence on the ease of spread and activity of the gonococcus?

(5) What is the significance of a caruncle and of urethral redness? Are these to be regarded as merely signs of past trouble, or do they indicate a condition liable to become active again?

(6) Is there anything that determines the lighting up of old infections? or the recrudescence of more recent conditions?

Why should the gonococcus, carefully searched for during several weeks (or months), suddenly appearwith or without alteration in local signs and symptoms?

(7) What is the significance of the case in which gonococci cannot be found, and the history and local condidition are not very suggestive of a gonococcal infection, but which responds only to specific anti-gonococcal treatment? 